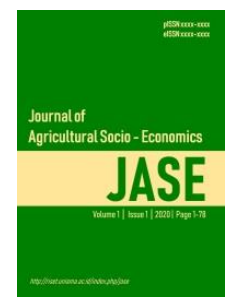

\title{
Penentu Respon Petani Terhadap Budidaya dan Pemanfaatan Sorgum: Studi Kasus di Desa Kawalelo Kecamatan Demon Pagong Kabupaten Flores Timur, NTT
}

\author{
Mathilda Bura Goran*, Ignatius Sinu, Marthen R. Pellokila \\ Universitas Nusa Cendana, Kupang, Nusa Tenggara Timur \\ *E-mail:marthenrpellokila@staf.undana.ac.id
}

\begin{abstract}
Sorghum is an important alternative food commodity for some rural communities in East Nusa Tenggata (NTT). This research is to find out the determinants of farmers' responses to the cultivation and utilization of sorghum in the research area. This study involved 30 respondents in sorghum cultivation and 30 respondents from non-sorghum cultivation which were found intentionally. Using survey methods to obtain data. Data were analyzed using the logistic regression model. The results of the study found that the factors that significantly influenced the cultivation and utilization of sorghum were non-formal education factors and the number of family dependents. This finding indicates that sorghum is used as an alternative food if staple food is reduced (entering a famine). The public needs to be educated and advocated that sorghum is not only used as an alternative food commodity in case of food shortages, but sorghum has high nutritional value and is easy to cultivate. Government intervention and the role of the community need to be increased in educating and advocating for farmers.
\end{abstract}

Keywords: response, sorghum, Logistic regression model

Abstrak. Sorgum merupakan salah satu jenis komoditi pangan alternatif penting bagi sebagian masyarakat desa di Nusa Tenggara Timur (NTT). Penelitian ini bertujuan untuk menemukan faktor penentu respon petani terhadap budidaya dan pemanfaatan sorgum di wilayah penelitian. Penelitian ini melibatkan 30 responden budidaya sorgum dan 30 responden bukan budidaya sorgum yang ditemukan secara sengaja. Menggunakan metode survei untuk memperoleh data. Data dianalisis mengunakan model regresi logistik. Hasil penelitian ditemukan bahwa faktorfaktor yang berpengaruh nyata terhadap budidaya dan pemanfaatan sorgum adalah faktor pendidikan non formal dan faktor jumlah tanggungan keluarga. Temuan ini memberikan indikasi bahwa sorgum dimanfaatkan sebagai pangan alternatif jika pangan pokok berkurang (memasuki masa paceklik). Masyarakat perlu diedukasi dan diadvokasi bahwa sorgum tidak saja dijadikan komoditi pangan alternatif jika terjadi keurangan pangan, tapi sorgum memiliki nilai gizi yang tinggi dan mudah dibudidayakan. Intervensi pemerintah dan peran masyarakat perlu ditingkatkan dalam mengedukasi dan advokasi para petani.

Kata Kunci: response, sorghum, Logistic regression model

\section{PENDAHULUAN}

Sektor pertanian merupakan sektor yang sangat penting dalam pembangunan perekonomian nasional karena Negara Indonesia merupakan negara agraris sehingga sektor pertanian menjadi sektor pemimpin dalam pembangunan perekonomian nasional. Salah satu sub sektor yang erat kaitannya dengan sektor pertanian adalah tanaman pangan. Pengembangan sektor tanaman pangan merupakan kunci dalam pertumbuhan ekonomi di masa yang akan datang. Pembangunan di bidang tanaman pangan akan mewujudkan pertanian yang efisien dan maju. Komoditi pangan merupakan komoditi yang terus dihasilkan oleh sektor pertanian dan digunakan oleh konsumen sehingga perlu adanya pengamanan komoditi pangan. Keamanan komoditi pangan turut mendukung program pemerintah dalam mengatasi kerawanan pangan.

Untuk mengatasi masalah kerawanan pangan pemerintah mengeluarkan program yaitu dengan cara penganekaragaman pangan. Melalui program yang diterapkan diharapkan agar masyarakat tidak 
hanya mengandalkan beras sebagai makanan pokok, tetapi diharapkan agar dapat memanfaatkan bahan pangan lainnya sebagai pengganti beras namun tetap memiliki nilai gizi yang setara dengan beras. Penganekaragaman tersebut dapat dilakukan dengan cara memanfaatkan bahan pangan yang lainnya seperti singkong, jagung, ubi jalar, talas dan sorgum. Perubahan struktur sektor pertanian direflesikan oleh perubahan-perubahannya dalam proses pengelolaan sumber daya ekonomi yang tidak lagi hanya berorientasi kepada upaya peningkatan produksi tetapi juga kepada upaya peningkatan pendapatan dan kesejahteraan masyarakat (Wibowo, 2000).

Salah satu komoditi pangan yang belum banyak dibudidayakan di Indonesia adalah tanaman sorgum karena jenisnya yang langka. Namun sebenarnya membudidayakan tanaman ini bukan hal yang sulit karena secara teknis budidaya tanaman ini tidak jauh berbeda dengan budidaya tanaman jagung. Sorgum menjadi salah satu tanaman pangan yang telah sukses dikembangkan di dunia terutama negaranegara maju seperti Amerika sehingga memiliki nilai jual yang tinggi. Sedangkan di Indonesia, sorgum berada pada tahap pengenalan dan pengembangan. Dengan demikian sorgum menjadi suatu inovasi untuk dunia pertanian di Indonesia. Sorgum sebagai suatu inovasi menambah keanekaragaman tanaman pangan yang sekaligus dapat mengurangi impor. Sorgum dapat dibudidayakan di lahan marjinal sebagai upaya optimalisasi lahan kritis yang kurang termanfaatkan. Hal ini dikarenakan sifat tanaman yang secara teknis budidaya mudah, tidak membutuhkan banyak air, dan dapat dikembangkan secara optimal hasilnya. Hal ini merupakan sebuah inovasi yang sekaligus dapat memanfaatkan lahan.

Sorgum (Sorghum bicolor L.) merupakan tanaman serealia yang dapat dikembangkan untuk menunjang ketahanan pangan. Tanaman ini memiliki adaptasi yang luas sehingga mampu tumbuh pada lahan marginal dan dapat dipanen beberapa kali (Mudjisihono dan Suprapto, 1987), kebutuhan airnya sedikit (150-200 mm/musim), dan lebih tahan penyakit. Kandungan nutrisi juga mendekati beras dan gandum. Kandungan karbohidrat sorgum $73,8 \%$, sedangkan beras $76 \%$ dan tepung terigu $77 \%$ (Suarni dan Firmansya, 2016). Hasil panen berupa biji dan biomassa sorgum dapat dimanfaatkan. Batang sorgum dapat diperas untuk diambil niranya dan dimanfaatkan sebagai bahan baku bioetanol. Biji sorgum dapat dimanfaatkan sebagai bahan pangan dan pakan, dan daun dari sorgum dapat dijadikan pakan ternak (Purnomohadi, 2006).

Sebagaimana yang kita ketahui bahwa dalam pengetahuan suatu inovasi baru yang diberikan kepada petani tidak akan begitu saja diterima atau ditolak oleh petani. Karena sebelum petani mencoba menerapkan inovasi/adopsi inovasi tersebut didahului oleh proses mental dan daya pikir yang terjadi dalam diri petani yang dimulai dari mengetahui, menaruh minat, melakukan penilaian, mencoba hingga mau menerapkan inovasi yang baru tersebut (Kartasapoetra, 1994:79). Petani yang telah coba menerapkan budidaya dan pemanfaatan sorgum harus benar-benar menguasai materi yang diberikan oleh penyuluh pertanian tentang teknologi budidaya dimulai dari pengolahan tanah hingga pemanenan serta pemanfaatannya. Adopsi inovasi merupakan hasil akhir dari komunikasi inovasi setelah unsur yang terkait diperhatikan serta dilaksanakan, terutama unsur-unsur yang secara langsung mempengaruhi proses adopsi suatu inovasi. Banyak aspek yang harus diperhatikan karena memiliki pengaruh sangat besar dalam menentukan keberhasilan adopsi inovasi oleh para petani. Unsur-unsur tersebut bekerja dalam suatu sistem yang saling mempengaruhi satu dengan yang lainnya. Karena semua unsur tersebut memiliki pengaruh terhadap proses adopsi inovasi, maka setiap unsur diperhatikan secara saksama. Sistem adopsi inovasi adalah kesatuan fungsi dari unsur-unsur seperti; tahap adopsi, kategori adopter, faktor-faktor yang berpengaruh dan peranan penyuluh.

Salah satu wilayah yang memiliki lahan marjinal yang berpotensial untuk ditanami tanaman sorgum adalah Provinsi NTT, karena kondisi geografi dan curah hujan rendah merupakan salah satu pembatas dalam mengusahakan tanaman pangan pokok seperti padi dan jagung namun sorgum mempunyai daya adaptasi yang tinggi terhadap kekeringan dan relatif tahan terhadap serangan hama dan penyakit. Mekanisme ketahanan sorgum terhadap kekeringan disebabkan oleh sistem perakaran sorgum yang lebat, ekstensif dan bercabang, sehingga apabila terjadi stress kekeringan maka sistem perakaran dengan cepat menyerap air sehingga terjadi pemulihan secara cepat.

Melihat keunggulan sorgum di atas, maka pengembangan sorgum di NTT perlu digalakkan, untuk mengangkat kembali bahan pangan lokal sebagai pengganti beras untuk mengatasi kerawanan pangan. Usaha pengembangan sorgum di NTT sudah mulai digalakkan. Salah satu daerah pengembangan sorgum di NTT adalah Kabupaten Flores Timur dengan hasil sebagai berikut; 
Tabel 1. Luas areal dan produksi sorgum di Kabupaten Flores, Nusa Tenggara Timur, Tahun 2016-2018

\begin{tabular}{ccccc}
\hline No & Tahun & $\begin{array}{c}\text { Luas Areal Penanaman } \\
(\text { Ha) }\end{array}$ & Produksi (Ton) & Keterangan \\
\hline 1. & 2016 & 35 & 129 & - \\
2. & 2017 & 160 & 312 & Naik \\
3. & 2018 & 138 & 268 & Turun \\
\hline
\end{tabular}

Berdasarkan Tabel 1 dapat dijelaskan bahwa produksi sorgum mengalami kenaikan pada tahun 2017 namun mengalami penurunan pada tahun 2018. Oleh karena itu Peneliti merasa perlu melakukan penelitian tentang faktor-faktor yang mempengaruhi petani dalam membudidayakan dan memanfaatkan sorgum, karena menjadi hal yang penting dalam menentukan perilaku atau respon petani sebagai pelaku utama yang akhirnya menentukan berlanjutnya kegiatan. Berdasarkan uraian yang telah dikemukakan, maka rumusan masalah yang diteliti yaitu; faktor-faktor apa saja yang mempengaruhi respon petani terhadap budidaya dan pemanfaatan sorgum di Desa Kawalelo, Kecamatan Demon Pagong, Kabupaten Flores Timur.

\section{METODE}

\subsection{Lokasi dan Waktu Penelitian}

Penelitian ini telah dilakukan di lakukan di Desa Kawalelo Kecamatan Demon Pagong Kabupaten Flores Timur. Penentuan desa lokasi penelitian dilakukan dengan cara purposive sampling (secara sengaja) dengan pertimbangan bahwa Desa Kawalelo merupakan desa pengembangan sorgum.

\subsection{Jenis dan Sumber Data}

Jenis data yang digunakan adalah data primer dan data sekunder. Metode pengumpulan data primer adalah metode survei dengan melakukan wawancara yang berpedoman pada daftar pertanyaan yang telah disiapkan. Sedangkan perolehan data sekunder adalah dengan cara mengambil data pada pihak terkait seperti Dinas Pertanian, Dinas Badan Pusat Statistik.

\subsection{Metode Penentuan Responden}

Penentuan responden diambil secara sengaja yaitu sebanyak 60 orang petani yang terbagi atas 30 petani yang sudah menanam sorgum dan 30 petani yang belum menanam sorgum dengan pertimbangan bahwa penelitian yang dilakukan adalah untuk menentukan faktor yang mempengaruhi mengapa ada petani yang menanam sorgum sedangkan ada yang tidak menanam sorgum, sehingga responden yang dibutuhkan adalah petani sorgum dan petani non sorgum.

\subsection{Analisis Data}

Untuk menjawab tujuan di atas, yakni untuk mengetahui faktor-faktor yang mempengaruhi respon petani terhadap budidaya dan pemanfaatan sorgum maka digunakan uji regresi logistik, yaitu dengan rumus:

$$
\begin{aligned}
& \operatorname{Ln} \frac{\pi_{i}}{\left(1-\pi_{i}\right)}=\alpha+\sum_{j=1}^{n} \beta_{i} X_{j i}+ \\
& \sum_{k=1}^{m} \gamma_{k} D_{k i}+\text { e. } \\
& \operatorname{Ln} \frac{\pi_{i}}{\left(1-\pi_{i}\right)}=\alpha+\beta_{1} \text { umur }+\beta_{2} \text { tingkat } \\
& \text { pendidikan }+\beta_{3} \text { pendapatan }+\beta_{4} \text { luas } \\
& \text { lahan }+\beta_{5} \text { pengalaman }+\beta_{6} \text { jumlah } \\
& \text { tanggungan keluarga }+\gamma D_{\text {seas }} \\
& \text { (peubah boneka). }
\end{aligned}
$$


HASIL DAN PEMBAHASAN

\subsection{Model Regresi Logistik}

Tabel 1. Model Regresi Logistik

\begin{tabular}{llllllll}
\hline & & \multicolumn{9}{c}{ Variables in the Equation } & \\
& & B & S.E. & Wald & Df & Sig. & Exp(B) \\
\hline Step & X3 & 3.661 & 1.093 & 11.218 & 1 & .001 & 38.883 \\
$1^{\text {a }}$ & X4 & 2.725 & 1.300 & 4.394 & 1 & .036 & 15.261 \\
& Constant & -3.317 & 1.311 & 6.407 & 1 & .011 & .036 \\
\hline
\end{tabular}

a. Variable(s) entered on step 1: X3, X4

Sumber : Data Primer Diolah, Tahun 2020

Berdasarkan rumus regresi logistik yang digunakan, yaitu

$\operatorname{Ln} \frac{\pi_{i}}{\left(1-\pi_{i}\right)}=\alpha+\sum_{j=1}^{n} \beta_{i} X_{j i}+$

$\sum_{k=1}^{m} \gamma_{k} D_{k i}+\mathrm{e}$

$\operatorname{Ln} \frac{\pi_{i}}{\left(1-\pi_{i}\right)}=\alpha+\beta_{1}$ umur $+\beta_{2}$ tingkat

pendidikan formal $+\beta_{3}$ tingkat

pendidikan non formal $+\beta_{4}$ jumlah

tanggungan keluarga $+\beta_{5}$ luas lahan +

$\beta_{6}$ pendapatan $+\beta_{7}$ pengalaman +

$\gamma D_{\text {seas }}$ (peubah boneka).

Maka dari Tabel diatas diperoleh persamaan regresinya adalah;

$\operatorname{Ln} \frac{\pi_{i}}{\left(1-\pi_{i}\right)}=-3,317+3,661$ pendidikan

non formal $+2,725$ jumlah

tanggungan keluarga.

$\operatorname{Ln} \frac{\pi_{i}}{\left(1-\pi_{i}\right)}=-3,317+3,661 \times 3+$

$2,725 \times 4$

Pada persamaan di atas dapat dilihat bahwa nilai untuk pendidikan non formal dan jumlah tanggungan keluarga bernilai positif. Hal ini berarti hubungan kedua variabel tersebut dengan variabel respon petani dalam budidaya dan pemanfaatan sorgum berbanding lurus. Jika setiap nilai pendidikan non formal dan jumlah tanggungan keluarga naik maka akan meningkatkan respon petani dalam budidaya dan pemanfaatan sorgum.

Berdasarkan hasil pada Tabel 1, terlihat nilai $\operatorname{Exp}(B)$ pada faktor/variabel pendidikan non formal (X3) sebesar 38,883 yang merupakan nilai terbesar dari variabel lainnya. Hal ini menunjukan bahwa faktor pendidikan non formal memiliki pengaruh paling besar daripada faktor yang lainnya karena dalam hubungan dengan budidaya dan pemanfaatan sorgum, pendidikan non formal merupakan salah satu faktor penting yang dapat mempengaruhi atau mendorong seseorang untuk melakukan usahatani tersebut, karena tanpa adanya pendidikan non formal seseorang bisa saja enggan atau tidak mau melakukan usahatani itu. Dengan demikian kegiatan penyuluhan dari dinas atau lembaga terkait sangat diperlukan guna mendukung para petani dalam melakukan kegiatan usahataninya.

\subsection{Uji Parsial}

Pengujian secara parsial dilakukan untuk mengetahui signifikansi setiap parameter variabel respon. Pengujian ini menggunakan tingkat signifikan $\alpha=0,05$ dengan keputusan hipotesis $\mathrm{H}_{-} 0$ ditolak apabila tingkat signifikansinya lebih kecil dari $\alpha$. 
Tabel 2. Tabel Hasil Uji Wald

\begin{tabular}{|c|c|c|c|c|c|c|c|c|}
\hline \multicolumn{9}{|c|}{ Variables in the Equation } \\
\hline & & B & S.E. & Wald & Df & & Sig. & $\operatorname{Exp}(B)$ \\
\hline \multirow[t]{3}{*}{ Step $1^{\mathrm{a}}$} & X3 & 3.661 & 1.093 & 11.218 & & 1 & .001 & 38.883 \\
\hline & $\mathrm{X} 4$ & 2.725 & 1.300 & 4.394 & & 1 & .036 & 15.261 \\
\hline & Constant & -3.317 & 1.311 & 6.407 & & 1 & .011 & .036 \\
\hline
\end{tabular}

a. Variable(s) entered on step 1: X3, X4.

Sumber: Data Primer Diolah, Tahun 2020

Berdasarkan Tabel 2 di atas menjelaskan bahwa variabel pendidikan non formal (X3) dan jumlah tanggungan keluarga (X4) merupakan parameter yang sigifikan dikarenakan nilai sig dari ke dua variabel tersebut lebih kecil dari 0,05. Sedangkan koefisien dari variabel umur (X1), pendidikan formal (X2), luas lahan (X5), pendapatan (X6) danpengalaman (X7) merupakan parameter yang tidak signifikan dikarenakan nilai sig dari ke lima variabel tersebut lebih besar dari 0,05. Sehingga dapat disimpulkan bahwa pada tingkat signifikansi 5\%, variabel pendidikan non formal dan jumlah tanggungan keluarga berpengaruh signifikan terhadap respon petani dalam budidaya dan pemanfaatan sorgum.

Uji ini dilakukan untuk menguji apakah variabel-variabel prediktor bersama-sama berpengaruh terhadap variabel respon, atau dengan kata lain apakah variabel-variabel $\mathrm{X}$ secara serentak berpengaruh berpengaruh terhadap variabel Y. Untuk menguji signifikansi model secara bersama-sama/serentak ini menggunakan uji rasio likelihood dengan ketentuan $\mathrm{H}_{-} 0$ ditolak apabila nilai p-value $(\operatorname{sig})<\alpha(0,05)$.

\subsection{Uji Rasio Likelihood}

Tabel 3. Tabel Uji Rasio Likelihood

\begin{tabular}{|c|c|c|c|c|}
\hline \multicolumn{5}{|c|}{ Omnibus Tests of Model Coefficients } \\
\hline & & Chi-square & Df & Sig. \\
\hline \multirow[t]{3}{*}{ Step 1} & Step & 27.824 & 2 & .000 \\
\hline & Block & 27.824 & 2 & .000 \\
\hline & Model & 27.824 & 2 & .000 \\
\hline
\end{tabular}

Sumber Data Primer Diolah, Tahun 2020

Dari Tabel 3 di atas diketahui bahwa nilai p-value $($ sig $)<$ dari nilai $\alpha(0,05)$ sehingga dapat disimpulkan bahwa $\mathrm{H} \_0$ ditolak yang artinya dari ke tujuh variabel-variabel bebas tersebut signifikan mempengaruhi respon petani dalam budidaya dan pemanfaatan sorgum.

Dari Tabel 3 juga dapat diketahui bahwa nilai chi square 27,824 > nilai chi square tabel pada DF 2 (jumlah variabel independen 2) yaitu 5,991 atau nilai sig nya sebesar 0,000 yang lebih kecil dari nilai $\alpha(0,05)$ sehingga memperoleh keputusan H_0 ditolak yang artinya bahwa penambahan variabel independen dapat memberikan pengaruh nyata terhadap model atau model dinyatakan FIT.

\subsection{Estimasi Parameter Model}

Uji estimasi parameter model dilakukan untuk melihat kemampuan variabel independen dalam menjelaskan variabel dependen, dengan menggunakan nilai Cox \& Snell R Square dan Nagelkerke R Square.

Tabel 4. Uji Estimasi Parameter Model

\begin{tabular}{crrr}
\hline \multicolumn{4}{c}{ Model Summary } \\
Step & -2 Log likelihood & Cox \& Snell R Square & Nagelkerke R Square \\
\hline \multicolumn{1}{c}{$55.354^{\text {a }}$} & .371 & .495 \\
\hline
\end{tabular}

Nilai Nagelkerke R Square pada Tabel 4 sebesar 0,495 dan Cox \& Snell R Square sebesar 0,371. Hal ini menunjukkan bahwa kemampuan variabel independen dalam menjelaskan variabel dependen adalah sebesar 0,495 atau sebesar $49,5 \%$ yang artinya respon petani dalam budidaya dan pemanfaatan sorgum dijelaskan oleh variabel independen sebesar $49,5 \%$ yaitu variabel pendidikan non formal dan jumlah tanggungan keluarga sedangkan 50,5\% lainnya dipengaruhi atau dijelaskan oleh variabel lainnya yang tidak dimasukkan dalam penelitian ini. 


\subsection{Ketetapan Klasifikasi}

Persentase ketetapan klasifikasi adalah ratio antara jumlah observasi yang diklasifikasikan secara tepat oleh model dengan jumlah seluruh observasi.

Tabel 5. Tabel Hasil Ketetapan Klasifikasi

\begin{tabular}{|c|c|c|c|c|c|}
\hline \multicolumn{6}{|c|}{ Classification Table $^{a}$} \\
\hline & & & \multicolumn{3}{|c|}{ Predicted } \\
\hline & & & $\mathrm{Y}$ & & \\
\hline & \multicolumn{2}{|c|}{ Observed } & .00 & 1.00 & Percentage Correct \\
\hline \multirow[t]{3}{*}{ Step 1} & $\mathrm{Y}$ & .00 & 28 & 2 & 93.3 \\
\hline & & 1.00 & 12 & 18 & 60.0 \\
\hline & & Overall Percentage & & & 76.7 \\
\hline
\end{tabular}

a. The cut value is .500

Sumber: Data Primer Diolah, Tahun 2020

Mengacu Tabel 5 yaitu hasil ketetapan klasifikasi di atas, dapat diketahui bahwa respon petani dalam budidaya dan pemanfaatan sorgum dari 60 petani responden yang menanam dan memanfaatkan sorgum sebanyak 20 petani, dan yang tidak budidaya dan memanfaatkan sorgum sebanyak 40 petani. Namun pada kenyataannya dari 60 petani responden yang menanam sorgum adalah sebanyak 30 petani dan yang tidak membudidayakan sorgum sebanyak 30 petani. Jadi, model regresi logistik yang digunakan cukup baik karena mampu menebak dengan benar 76,7\% kondisi yang terjadi.

\subsection{Interpretasi Koefisien (Odds Ratio)}

Interpretasi koefisien dilakukan untuk menggambarkan besarnya kecenderungan hasil tertentu muncul diantara kelompok yang memiliki karakter tertentu dibandingkan dengan kelompok pembanding. Nilai odds ratio masing-masing variabel prediktor yang berpenagruh terhadap variabel 6.

Tabel 6. Interpretasi Koefisien Regresi Logit

\begin{tabular}{llllllll}
\hline & & \multicolumn{6}{c}{ Variables in the Equation } \\
& & B & S.E. & Wald & Df & Sig. & Exp(B) \\
\hline Step & X3 & 3.661 & 1.093 & 11.218 & 1 & .001 & 38.883 \\
$1^{\text {a }}$ & X4 & 2.725 & 1.300 & 4.394 & 1 & .036 & 15.261 \\
& Constant & -3.317 & 1.311 & 6.407 & 1 & .011 & .036 \\
\hline
\end{tabular}

a. Variable(s) entered on step 1: X3, X4.

Sumber: Data Primer Diolah, Tahun 2020

Dari Tabel di atas, dapat dilakukan interpretasi odds ratio masing-masing variabel adalah sebagai berikut: Pendidikan non formal (X3).Untuk variabel pendidikan non formal diperoleh nilai odds ratio sebesar 38,883. Dari nilai tersebut dapat diartikan bahwa petani yang memiliki atau mengikuti pendidikan non formal cenderung lebih memilih untuk melakukan budidaya dan pemanfataan sorgum sebesar 38,883 kali dibandingkan dengan petani yang tidak mengikuti pendidikan non formal.

Hasil penelitian ini sebanding dengan hasil penelitian Bambang Siswadi dan Farida Syakir tentang respon petani terhadap program pemerintah mengenai Asuransi Usahatani Padi (AUTP) yang menyatakan bahwa pendidikan non formal berpengaruh nyata sebagaimana ditunjuk dengan nilai 『Wald】_hitung $(Z)=1,69$, nilai p-value 0,091 yang mana angka tersebut lebih kecil dari 0,10 , yang berarti H_1 diterima atau pendidikan non formal berpengaruh nyata terhadap respon petani padi mengenai program AUTP. Koefisien regresi pendidikan non formal bernilai positif sebesar 0,186221 memberikan arti bahwa semakin sering petani mengikuti penyuluhan maka peluang untuk respon terhadap program AUTP semakin besar.

Hal ini selaras dengan pendapat Soekarwati (1999) bahwa agen penyuluh dapat membantu petani memahami besarnya pengaruh struktur sosial ekonomi dan teknologi untuk mencapai kehidupan yang lebih baik dan menemukan cara mengubah struktur atau situasi yang menghalangi untuk mencapai 
tujuan tersebut. Semakin tinggi keikutsertaan mengikuti penyuluhan makaa keberhasilan penyuluhan pertanian yang disampaikan semakin tinggi pula.

Jumlah tanggungan keluarga (X4). Untuk variabel jumlah tanggungan keluarga diperoleh nilai odds ratio sebesar 15,261. Dari nilai tersebut dapat diartikan bahwa petani yang memiliki jumlah tanggungan keluarga diatas dua orang akan cenderung melakukan budidaya dan pemanfaatan sorgum sebesar 15,261 kali dibandingkan dengan petani yang memiliki jumlah tanggungan keluarga dibawah dua orang.

Hasil penelitian ini sebanding dengan hasil penelitian Moh.Sahril Tupua yang berjudul faktorfaktor yang mempengaruhi keputusan petani beralih usahatani padi sawah ke jagung yang mengatakan bahwa variabel jumlah anggota keluarga berpengaruh terhadap peralihan usahatani dari padi sawah ke jagung. Hal ini ditunjukan oleh nilai koefisien regresi yang bernilai positif dan nilai p-value sebesar 0,051 kurang dari 0,1 dengan tingkat kepercayaan $90 \%$ yang artinya petani memiliki jumlah anggota keluarga lebih banyak mempenyai peluang untuk beralih dari usahatani padi sawah ke jagung yang diperkuat dengan angka odds ratio sebesar 1,46 yang artinya bahwa petani yang memiliki jumlah anggota keluarga lebih banyak memiliki peluang untuk melakukan peralihan usahatani sebesar 1,46 kali dibandingkan petani yang memiliki jumlah anggota keluarga lebih sedikit.

Menurut Mosher (1985), mengatakan bahwa keluarga merupakan salah satu faktor yang mempengaruhi petani dalam pengambilan keputusan untuk pengelolaan usahataninya. Oleh karena keluarga merupakan tanggung jawab setiap kepala keluarga maka menimbulkan keinginan, dorongan dan motivasi untuk kepala keluarga (dalam hal ini petani responden) untuk melakukan usahatani agar dapat membantu kehidupan ekonomi keluarganya agar lebih sejahtera.

\section{KESIMPULAN}

Berdasarkan tujuan dari penelitian ini, yaitu tentang faktor-faktor yang mempengaruhi respon petani terhadap budidaya dan pemanfaatan sorgum, maka kesimpulan yang dapat diambil adalah dari ke tujuh variabel bebas/faktor yang mempengaruhi yakni umur (X1), pendidikan formal (X2), pendidikan non formal (X3), jumlah tanggungan keluarga (X4), luas lahan (X5), pendapatan (X6) dan pengalaman (X7) yang berpengaruh signifikan terhadap respon petani terhadap budidaya dan pemanfaatkan sorgum adalah faktor pendidikan non formal (X3) dan faktor jumlah tanggungan keluarga (X4), di mana petani lebih cenderung mengusahakan sorgum apabila jumlah tanggungan keluarga petani lebih dari dua orang dan petani yang pernah mengikuti pendidikan non formal karena hanya lewat pendidikan non formal yang berupa penyuluhan atau pelatihan dari dinas atau lembaga terkait sangat mendorong dan membantu petani dalam budidaya dan pemanfaatan sorgum serta dapat menjawab permasalahan yang mungkin sedang dihadapi petani, sedangkan untuk responden yang belum menanam sorgum itu pada umumnya adalah responden yang belum mengikuti pendidikan non formal.

Persamaan regresi logistik yang dihasilkan dari model adalahLn $\frac{\pi_{i}}{\left(1-\pi_{i}\right)}=-3,317+3,661 \mathrm{X} 3+$ 2,725X4yang artinya semakin bertambah nilai pendidikan non formal maka kecenderungan petani mengusahakan sorgum semakin meningkat dan semakin banyak jumlah tanggungan keluarga maka semakin tinggi pula kecenderungan petani untuk mengusahakan sorgum. Dengan nilai ketetapan klasifikasi respon petani dalam budidaya dan pemanfaatan sorgum dengan menggunakan analisis regresi logistik adalah sebesar $76,7 \%$.

\section{DAFTAR PUSTAKA}

Adiwilaga, A. 1987. Ilmu Usahatani. Alumni. Jakarta.

Badan Pusat Statistik Kabupaten Flores Timur 2019. Kabupaten Flores Timur dalam angka 2019. Katalog 1102001.5309

Gibson, J.L, Ivancevich, J.M. Donnely, J.H, and Konopaske, R. 2003.“Organizations : Behavior, Structure, Process" (Eleventh Edition). Boston : McGraw-Hill Irwin

Ismail, G. I dan A. Kodir. 1977. Cara Bercocok Tanam Sorgum. Buletin teknik lembaga pusat penelitian pertanian Bogor (2). 1-9

Kartono, K. 2000. Hygiene Mental. Bandung

Mosher, A. T. 1985. Membangun dan Menggerakan Pertanian di Indonesia. Yasaguna. Jakarta

Mudjisihono dan Suprapto. 1987. Budidaya dan pengolahan sorgum. Penebar Swadaya, Jakarta. NCDC NOAA. 2018. 
Nurjanah A. 2017. Analisis Nilai Tambah Dan Startegi Pengembangan Tepung Sorgum Pada Agroindustri Di Desa Patihan Kecamatan Babat Kabupaten Lamongan. Skripsi. Jurusan Sosial Ekonomi Fakultas Pertanian Universitas Brawija, Malang. Diunduh dari http://repository.ub.ac.id/6830/1/ALFI\%20NURJANAH.pdf

Purnomohadi M. 2006. Potensi Penggunaan Beberapa Varietas Sorgum Manis (Sorghum bicolor (L.) Moench) sebagai Tanaman Pakan. J Berkala Hayati, 12:41-44

Rismunandar, dan F.H. Fraeyhoven. 1973. Sorgum Tanaman Serba Guna. N. V Masa Baru, Bandung

Sajogyo dan Pujiwati Sajogyo. 1982. Sosiologi Pedesaan. Jilid 1. Gadjah Mada University Press. Jogyakarta.

Shiska M, dan Sutejo.2018. Persepsi Ibu Rumahtangga Terhdap Produk Tempe Sorgum Dan Strategi Pengembangannya Di Kabupaten Musi Rawas. Fakultas Pertanian Universitas Musi Rawas. Jurnal SocietaVII-

1:51-59, Jun 2018. Diunduh dari https://jurnal-um-palembang.ac.id/societa/article/download/1136/974

Siswadi dan Syakir.2016.Respon Petani Terhadap Program Pemerintah MengenaiAsuransi Usahatani Padi. Program Studi Agribisnis Fakultas Pertanian Universitas Islam Malang. Prosiding Seminar Nasional Pembangunan, Hal 169-177, 2016. Diunduh dari https://fp.ub.ac.id/semnas/Paper/29_asuransi_padi-bambang_siswadi-(169-177)pdf

Soehardjo dan Patong. 1978. Sendi-sendi Pokok Ilmu Usahatani. Departemen Sosial. FAPERTAIPB

Soekarwati. 1999. Agribisnis Teori dan Aplikasinya. Raja Grafindo Persada, Jakarta.

Suarni, IU Firmansyah. 2016. Struktur, Komposisi Nutrisi dan Teknologi Pengolahan Sorgum. Balai Penelitian Tanaman Serealia.Balitsereal.litbang.pertanian.go.id

Syafruddin M. Dkk. 2015. Strategi Pengembangan Sorgum Di Kabupaten Wonogiri. Program Studi Agribisnis Fakultas Pertanian, Universitas Sebelas Maret Surakarta. Jurnal Sosial Ekonomi Pertanian dan Agribisnis Vol .12 No. 1 Hal 70-81 September 2015. Diunduh dari https://jurnal.uns.ac.id/sepa/article/viewFile/14204/11822

Tabri Dkk.2014. Budidaya Tanaman Sorgum. Balai Penelitian Tanaman Serelia. Diunduh dari http://balitsereal.litbang.pertanian.go.id/wp-content/uploads/2016/11/fahdianas.pdf

Tupua, M.S. 2019. Faktor-Faktor Yang Mempengaruhi Respon Keputusan Petani Beralih Usahatani Padi Sawah Ke Jagung Di Desa Ambulu Kecamatan Sumberasih Kabupaten Probolinngo. Program Studi agribisnis Fakultas Pertanian Universitas Islam, Malang. Jurnal Sosial Ekonomi Pertanian Vol. 7 No. 4, 2019. Diunduh dari http://www.riset.unisma.ac.id/index.php/SEAGRI/article/viewFile/4591/4 164

Wibowo, Rudi. 2000. Pertanian dan Pangan Bunga Rampai Pemikiran Menuju Ketahanan Pangan. Sinar Harapan, Jakarta.

Wijayanti, A. Dkk. 2015. Respon Petani Terhadap Budidaya Dan Pemanfaatan Sorgum Kecamatan Srandakan Kabupaten Bantul. Penyuluhan Dan Komunikasi Pertanian. Jurnal Agro Ekonomi Vol.26 No.2, Hal 179-191 Desember 2015. Diunduh dari https://journal.ugm.ac.id/jae/article/download/17270/11261 